\title{
Monoclonal antibody against Rab8 from Bombyx mori (Lepidoptera: Bombycidae)
}

\author{
TOMOHIDE UNO ${ }^{1}$, TAKUYa NAKADA ${ }^{1}$, YUichi UNO ${ }^{2}$, Kengo KANAMARU $^{1}$, HiRoshi YAMAGATA ${ }^{1}$, \\ MASAHIKO NAKAMURA ${ }^{3}$ and MichIHIRO TAKAGI ${ }^{4}$ \\ ${ }^{1}$ Laboratory of Biological Chemistry, Department of Biofunctional Chemistry, Faculty of Agriculture, Kobe University, Nada-ku, \\ Hyogo 657-8501, Japan; e-mail: unotom@kobe-u.ac.jp \\ ${ }^{2}$ Department of Plant Resource Science, Faculty of Agriculture, Kobe University, Nada-ku, Hyogo 657-8501, Japan \\ ${ }^{3}$ Department of Bioscience and Biotechnology, Faculty of Bioenvironmental Science, Kyoto Gakuen University, 1-1 Nanjo, Sogabe, \\ Kameoka, Kyoto 621-8555, Japan \\ ${ }^{4}$ Department of Animal Science, Faculty of Agriculture, Kobe University, Nada-ku, Hyogo 657-8501, Japan
}

Key words. Bombyx mori, monoclonal antibody, Rab proteins, brain

\begin{abstract}
Small GTPases of the Rab family are key regulators of membrane trafficking. Monoclonal antibodies are useful tools for identifying proteins that interact with other proteins and for examining their tissue distribution. We selected a monoclonal antibody against Rab8 of Bombyx mori L. It specifically recognized amino acid residues 30-109, which are conserved among Rab8 proteins, and did not recognize any other Rab proteins. Western blotting using the antibody revealed one band in the brains of $B$. mori and rat. Far-Western blotting analysis detected three proteins interacting with Rab8. These results indicate that this antibody is useful for clarifying the physiological function of Rab8 of B. mori and other species. This is a report of a study on a monoclonal antibody against insect Rab protein.
\end{abstract}

\section{INTRODUCTION}

The Rab proteins comprise the largest subgroup of the Ras superfamily of small GTPases, which includes almost 70 members. These proteins act as regulators of trafficking between subcellular compartments in eukaryotic cells (Zerial et al., 2001; Deneka et al., 2003). Conserved regions are involved in guanine and phosphate/magnesium binding (Pereira-Leal \& Seabra, 2000). Like other GTPases, Rab proteins cycle between active GTP-bound and inactive GDP-bound forms. On the subcellular membrane, the GTP-bound form binds many effector proteins and carries out a variety of cellular processes (Jordens et al., 2005; Grosshans et al., 2006). After Rab proteins complete their designated function on the membrane, they return to the inactive GDP-bound form in the cytosol.

Insect $\mathrm{Rab}$ proteins also regulate important cellular processes such as eye development and cell polarity during oogenesis (Dollar et al., 2002; Pelissier et al., 2003; Debasmita et al., 2005; Satoh et al., 2005). Rab1 and Rab6 play important roles in processing and transport of rhodopsins (Satoh et al., 1997; Shetty et al., 1998). Rab5 is involved in trafficking at synapses (Wucherpfennig et al., 2003). But little is known about the biochemical, genetic, and functional features of Rab proteins of insects other than Drosophila.

Mammalian Rab8 has many functions, including the regulation of synaptic plasticity, neurite outgrowth and melanosome transport (Huber et al., 1993, 1995; Gerges et al., 2004; Chabrillat et al., 2005). In addition, it has been implicated in the neurodegenerative disorders Huntington's disease (Hattula \& Peranen, 2000; Sah- lender et al., 2005) and Alzheimer's disease (Kametani et al., 2004). But there is little information on the biochemical characteristics of insect Rab8. Further some functional proteins that interact with Rab8 in mammals were identified using a two-hybrid system (Huber et al., 1993, 1995; Gerges et al., 2004; Chabrillat et al., 2005; Sahlender et al., 2005). But these proteins have not been reported in insects.

We previously isolated $R a b 8$ cDNA from the brain of Bombyx mori. Rab8 proteins were produced in Escherichia coli, purified by affinity chromatography, and phosphorylated by protein kinase C (PKC) in vitro (Uno et al., $2004,2006)$. In contrast to in vitro analysis, monoclonal antibodies are useful tools for analyzing proteins in vivo. Immunoblotting will detect Rab proteins, far-Western blotting will detect proteins interacting with them, and, unlike in vitro analysis, immunohistochemistry will show the distribution of Rab proteins in tissues.

Here, we injected purified Rab8 of B. mori (BRab8) as an immunogen into mice, and isolated several monoclonal antibodies. A monoclonal antibody selected by ELISA specifically recognized amino acid residues (aa) 30-109 of Rab8.

\section{MATERIAL AND METHODS}

\section{Materials}

Thrombin, plasmid pGEX6P2, an mRNA purification kit, and glutathione-Sepharose came from GE Healthcare UK Ltd. (Little Chalfont, Bucks., England). PKC came from Upstate Biotechnology Inc. (Lake Placid, NY, USA). Ni-NTA Superflow resin came from Qiagen (Hilden, Germany). pET43a and pET32a came from Novagen (Darmstadt, Germany). pCR2.2 
came from Invitrogen Japan KK (Tokyo, Japan). Peroxidaseconjugated goat anti-mouse IgG came from Wako Pure Chemicals (Tokyo, Japan). Taq DNA polymerase, reverse transcriptase, and a DNA ligation kit came from Takara Shuzo (Kyoto, Japan). Ez West Blue reagent came from Atto Corp. (Tokyo, Japan). All other chemicals were of the purest grade commercially available.

We raised a hybrid race $($ Kinshu $\times$ Showa or Shunrei $\times$ Shogetsu) of B. mori. Larvae were reared on an artificial diet (Silkmate $2 \mathrm{M}$, Nosan Co., Yokohama, Japan) at $25^{\circ} \mathrm{C}$ under $16 \mathrm{~L}$ : $8 \mathrm{D}$ and $70 \%$ relative humidity. Day 2 fifth-instar larvae were used in the experiments.

\section{Purification of BRab proteins}

The cDNA fragment containing the entire coding sequence of BRab8 was obtained as described previously (Uno et al., 2006) and subcloned into pCR2.2. Sequence analysis was carried out using an ABI Prism 377 DNA sequencer. The plasmid was digested with BamHI and EcoRI. The digested fragment was then inserted between the BamHI and EcoRI sites of pET32a to encode thioredoxin fusion protein. E. coli cells (BL 21) were transformed with pET32a. Cells transformed with pET32a were incubated at $37^{\circ} \mathrm{C}$ for 3 to $4 \mathrm{~h}$ in LB (Luria-Bertani) medium until the O.D. at $600 \mathrm{~nm}$ reached 0.6. Production of the fusion protein was then induced by adjusting the culture to $1 \mathrm{mM}$ isopropyl $\beta$-D-thiogalactopyranoside and incubating for $3 \mathrm{~h}$ at $37^{\circ} \mathrm{C}$. The cells expressing the recombinant fusion proteins were collected by centrifugation for $10 \mathrm{~min}$ at $5000 \times \mathrm{g}$ and then stored at $-80^{\circ} \mathrm{C}$. Frozen cells from $1 \mathrm{~L}$ of culture were suspended in $10 \mathrm{~mL}$ of lysis buffer $\left(50 \mathrm{mM} \mathrm{Na} \mathrm{HPO}_{4}, 300 \mathrm{mM}\right.$ $\mathrm{NaCl}$, and $10 \mathrm{mM}$ imidazole, $\mathrm{pH} 8.0$ ) and disrupted by sonication and the solution cleared by centrifugation at $12000 \times \mathrm{g}$ for $40 \mathrm{~min}$. The fusion protein in the supernatant was then applied to $1 \mathrm{~mL}$ of Ni-NTA Superflow column and the column was washed with $10 \mathrm{~mL}$ of wash buffer $\left(50 \mathrm{mM} \mathrm{Na}_{2} \mathrm{HPO}_{4}, 300 \mathrm{mM}\right.$ $\mathrm{NaCl}$, and $20 \mathrm{mM}$ imidazole, $\mathrm{pH} 8.0$ ). Bound proteins were eluted from the resin with $5 \mathrm{~mL}$ of elution buffer $\left(50 \mathrm{mM} \mathrm{Na}_{2} \mathrm{H}-\right.$ $\mathrm{PO}_{4}, 300 \mathrm{mM} \mathrm{NaCl}$, and $100 \mathrm{mM}$ imidazole, $\mathrm{pH}$ 8.0). Eluted proteins were dialyzed against distilled water and freeze-dried.

Rab11, Rab1, Rab7, and Rab14 of B. mori (BRab11, BRab1, BRab7, and BRab14) were produced as GST-fusion proteins by the pGEX6P2 vector in $E$. coli and purified by glutathioneSepharose 4B column chromatography (Uno et al., 2004, 2006). Proteins were determined against bovine serum albumin (Fraction V, Sigma-Aldrich Japan, Tokyo, Japan ) as the standard by the method of Lowry et al. (1951).

\section{Immunization of mice and production of hybrid cells}

Specific-pathogen-free BALB/c mice were purchased from Japan SLC, Inc. (Shizuoka, Japan). Two 6-week-old female mice were acclimatized for 1 week, and treated according to the guidelines for animal experiments at Kobe University. BRab8 fusion protein $(100 \mu \mathrm{g})$ was emulsified in Titer-Max Gold (CytRx Corp., Norcross, GA, USA) and injected subcutaneously or intramuscularly into the mice once a week for 4 weeks. The mice were killed 3 days after the last injection. The spleens were extracted, and splenocytes were fused to P3U1 mouse myeloma cells in 50\% polyethylene glycol 1540 (Wako, Japan). Fused cells were gently re-suspended in RPMI-1640 medium containing 20\% fetal bovine serum (BioWest, Miami, FL, USA) and $100 \mu \mathrm{M}$ hypoxanthine, $4 \mu \mathrm{M}$ aminopterin, and $16 \mu \mathrm{M}$ thymidine (Invitrogen, Rockville, MD, USA). The production of antibody against BRab8 fusion protein by the hybridoma cells was determined by ELISA of the cell supernatant.

\section{Construction of deletion genes and expression in $E$. coli}

As shown in Fig. 3, three deletion plasmids (DR1-3) of BRab8 cDNA were constructed. To construct DR1 and DR2, two primers were used for PCR: 5'-CGGATCCAGTGCTGATGATGTTGAGAAAAT-3' and 5'-GGAATTCTCATGCTGATGTCTCCAC-3', and 5'-CGGATCCGATGCATTTTAACATCTCCTTTAT-3' and 5'-TTACTCTTCAATGTTCCTAATC-3', respectively. The amplified fragments were subcloned into pCR2.2. The plasmids were digested with $B a m \mathrm{HI}$ and EcoRI. Each digested fragment was then inserted into the BamHI and EcoRI sites of pET32a. To construct DR3, pET32 containing BRab8 cDNA was cut with NsiI and selfligated. E. coli cells (Rosetta) transformed with these plasmids were incubated at $37^{\circ} \mathrm{C}$. Thioredoxin-fusion proteins were induced by adjusting the culture to $1 \mathrm{mM}$ isopropyl â-Dthiogalactopyranoside and purified as described above.

\section{SDS-PAGE}

SDS-polyacrylamide gel analysis was performed according to the method of Laemmli (1970), using a 4.5\% stacking gel and a $15 \%$ separating gel, at a constant current of $16 \mathrm{~mA}$. The proteins were visualized with Coomassie brilliant blue (CBB) stain.

\section{Western blotting analysis}

Brains of $B$. mori or rat were homogenized in $50 \mathrm{mM}$ HEPES $\cdot \mathrm{HCl}(\mathrm{pH} 7.5)$ containing $20 \%$ glycerol, $1 \mathrm{mM}$ EDTA, and $1 \mathrm{mM}$ dithiothreitol and the solutions were diluted to 100 $\mu \mathrm{g}$ protein $/ 100 \mu \mathrm{L}$. Proteins $(10 \mu \mathrm{g})$ were separated by SDSPAGE and electrophoretically transferred to a nitrocellulose membrane. The membrane was blocked in Blocking One solution (Nakalai Tesque, Kyoto, Japan) at room temperature for 60 min. After washing three times with $10 \mathrm{~mL}$ of TBS containing $0.05 \%$ Tween $20(\mathrm{v} / \mathrm{v})$, the blot was incubated in $1 / 1000$ or $1 / 50$ anti-BRab8 antibody in TBS $(50 \mathrm{mM}$ Tris $\cdot \mathrm{HCl}, \mathrm{pH} 8.0$, and 50 $\mathrm{mM} \mathrm{NaCl}$ ) containing Blocking One. It was washed three times with $10 \mathrm{~mL}$ of TBS containing $0.05 \%$ Tween $20(\mathrm{v} / \mathrm{v})$. Next, it was incubated with $1: 2000$ peroxidase-conjugated goat antimouse IgG. After washing three times with $10 \mathrm{~mL}$ of TBS containing Tween-20, protein was detected using Ez West Blue reagents and the images were analyzed by GT-S 600 scanner (Epson Corp., Tokyo, Japan).

\section{Far-Western blotting}

Ten brains of $B$. mori were homogenized in $50 \mathrm{mM}$ HEPES $\cdot \mathrm{HCl}(\mathrm{pH} 7.5$ ) containing $20 \%$ glycerol, $1 \mathrm{mM}$ EDTA, and $1 \mathrm{mM}$ dithiothreitol and the solutions were diluted to 100 $\mu \mathrm{g}$ protein $/ 100 \mu \mathrm{L}$. Proteins $(10 \mu \mathrm{g})$ were separated by SDSPAGE and electrophoretically transferred to a nitrocellulose membrane. The membrane was blocked in Blocking One solution at $4{ }^{\circ} \mathrm{C}$ for $5 \mathrm{~h}$. The purified BRab8 protein $(10 \mu \mathrm{g} / \mathrm{mL})$ was added to the membrane in $5 \mathrm{~mL}$ of Blocking One solution and incubated at $4{ }^{\circ} \mathrm{C}$ overnight. After washing three times with 10 $\mathrm{mL}$ of TBS ( $50 \mathrm{mM}$ Tris $\cdot \mathrm{HCl}, \mathrm{pH} 8.0$, and $50 \mathrm{mM} \mathrm{NaCl}$ ) containing $0.05 \%$ Tween $20(\mathrm{v} / \mathrm{v})$, the blot was incubated in $1 / 2000$ anti-BRab8 antibody in $2 \mathrm{~mL}$ of TBS containing $0.1 \mathrm{~mL}$ of Blocking One solution at room temperature for $60 \mathrm{~min}$. After washing three times with $10 \mathrm{~mL}$ of TBS containing $0.05 \%$ Tween $20(\mathrm{v} / \mathrm{v})$, goat peroxidase-conjugated anti-mouse IgG was incubated as secondary antibody $(1 / 5000)$ at room temperature for $60 \mathrm{~min}$. After washing, the proteins were visualized using Ez West Blue (Atto Corp., Tokyo, Japan) and the images were analyzed by GT-S 600 scanner (Epson Corp., Tokyo, Japan). 


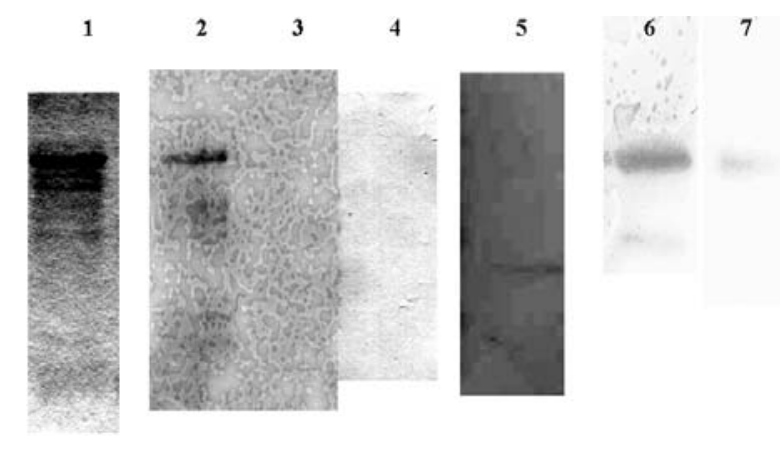

Fig. 1. Immunoblotting using monoclonal antibody. Purified protein $(1 \mu \mathrm{g})$ was electrophoresed, transferred to a nitrocellulose membrane, and immunostained. Lane 1, CBB staining of BRab8; 2-5, immunoblotting of BRab8 (2-4) or thioredoxin (5) using clone $1 ; 3$, control (supernatant from unfused cells was used in place of primary antibody); 4, control (antibody + antigen was used as primary antibody); 6, 7, immunoblotting of BRab8 using clone 2. Primary antibody was added at a dilution of $1 / 50$ (lane 6 ) or $1 / 1000(2-5,7)$.

\section{RESULTS}

\section{Isolation of monoclonal antibody against Rab8 of Bombyx mori}

To establish a monoclonal antibody against BRab8, we produced BRab8 protein in E. coli and purified it using a Ni-NTA Superflow column (Fig. 1, lane 1). Mice were immunized with this antigen, and hybridomas were pro-
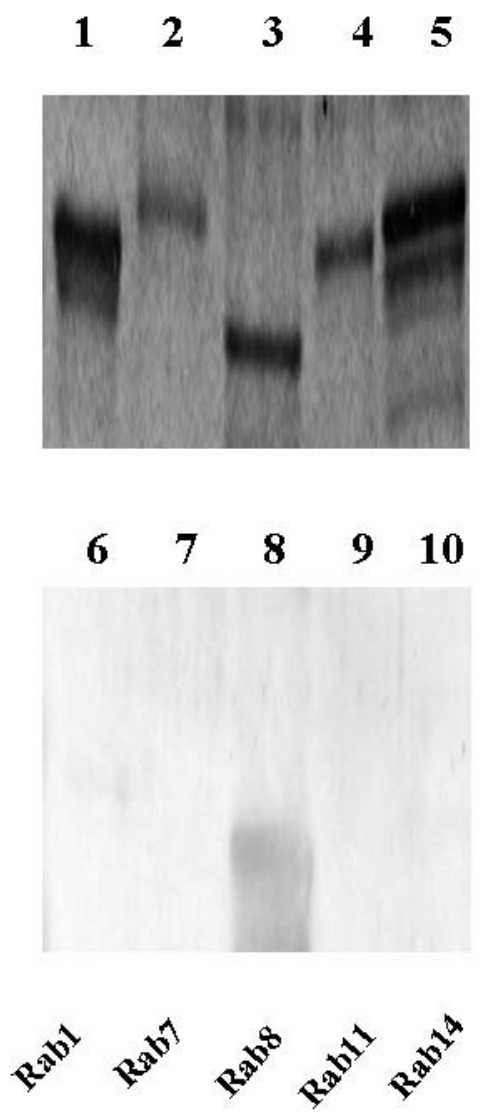

Fig. 2. Characteristics of monoclonal antibody. Purified Rab proteins $(3 \mu \mathrm{g})$ were electrophoresed and immunoblotted. Lanes $1-5$, CBB staining; lanes 6-10, immunoblotting.

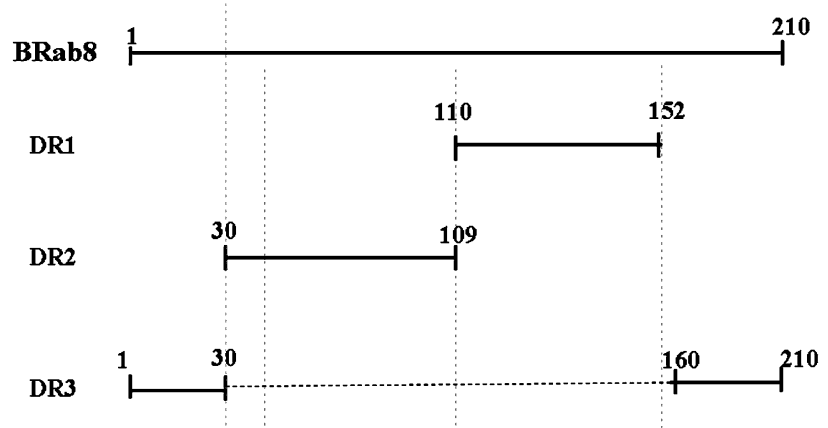

Fig. 3. Construction of $B R a b 8$ deletion plasmids. From fulllength $B R a b 8$ cDNA, three deletion fragments were constructed by PCR and cut with restriction enzymes. Positions of amino acids are shown.

duced. Many clones were isolated and incubated. Cells producing antibody against purified BRab8 were selected by ELISA.

Using the isolated antibodies, we carried out Western blotting (Fig. 1). The antibodies specifically recognized a protein band corresponding to the position of purified BRab8 on SDS-PAGE gel (Fig. 1, lanes 1, 2). Most showed low affinity to BRab8 on the nitrocellulose membrane: they reacted to a $1 / 50$ dilution (Fig. 1, lane 6), but not a 1/1000 dilution (Fig. 1, lane 7). One clone (clone 1) showed high sensitivity to BRab8, reacting to a $1 / 1000$ dilution (Fig. 1, lane 2). Two control experiments (adding culture supernatant from unfused cells in place of primary antibody; and adding antigen and primary antibody together) showed no band in immunoblotting (Fig. 1, lanes 3,4). BRab8 was expressed as thioredoxin fusion protein in $E$. coli, but the antibody did not recognize the protein (Fig. 1, lane 5). This result indicates that one monoclonal antibody with high affinity to BRab8 was isolated.
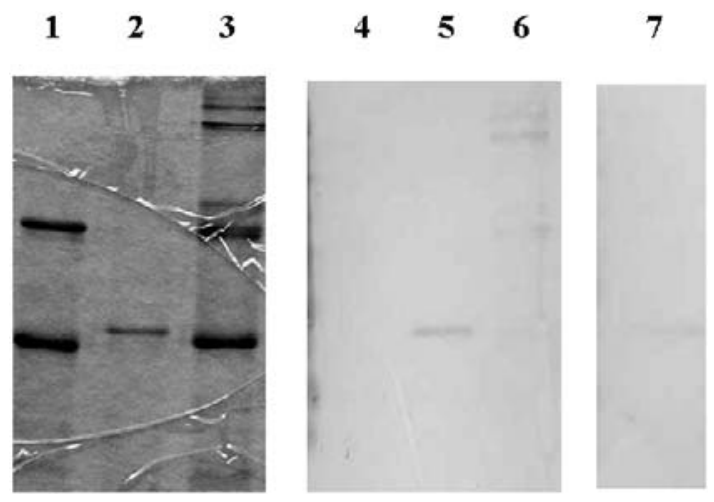

Fig. 4. Determination of amino acid regions of Rab8 recognized by antibody. Expressed proteins (DR1, lanes 1, 4; DR2, 2, 5,7 ; DR3, 3, 6) were purified, electrophoresed, and stained with CBB (1-3) or immunoblotted (4-7). Lane 7, antibody + antigen (DR2) was used as primary antibody. DR1, $3 \mu \mathrm{g}$; DR2, $1 \mu \mathrm{g}$; DR3, $3 \mu \mathrm{g}$. 


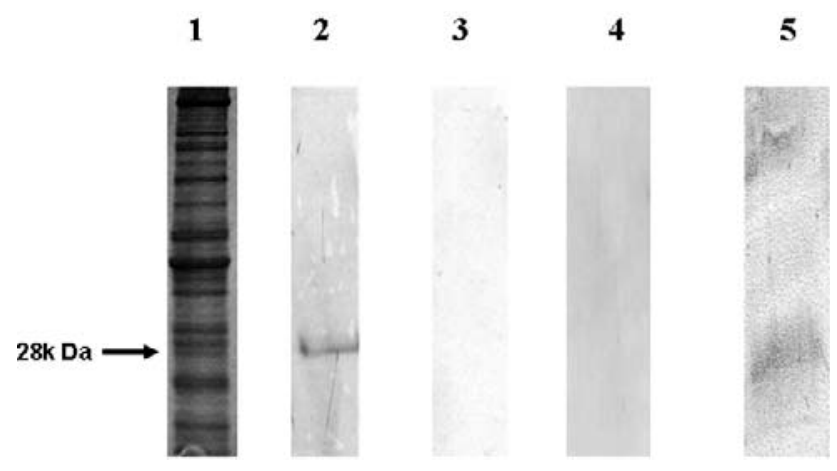

Fig. 5. Immunoblot analysis of BRab8 expression in the brains of Bombyx mori (lanes 1-4) and rat (5). After electrophoresis, proteins $(10 \mu \mathrm{g})$ were transferred to a nitrocellulose membrane and incubated with antibody (lanes 2, 5). Lane 1, CBB staining. Lane 3, control (non-immune cell supernatant was used as primary antibody); lane 4 , control (antibody + antigen was used as primary antibody). The arrow indicates Rab8 protein (MW; $28 \mathrm{kDa})$.

\section{Biochemical characteristics of monoclonal antibody}

To determine the specificity of this antibody, other Rab proteins were generated (BRab1, BRab7, BRab11, and BRab14), expressed as GST-fusion proteins, and purified. The purified Rab proteins were electrophoresed, transferred to membrane, and reacted with the BRab8 antibody (Fig. 2). Almost all of the clones reacted slightly to these other Rab proteins (data not shown), but clone 1 specifically interacted with BRab8.

To determine the region of BRab8 which the antibody recognized, we constructed three deletion plasmids of BRab8 cDNA (DR1-3; Fig. 3). The plasmids were transformed into $E$. coli, and the expressed proteins were purified using a Ni-NTA column (Fig. 4, lanes 1-3), electrophoresed and immunoblotted. Only one protein, containing aa 30-109 of BRab8 (DR2), was detected (Fig. 4, lane 5). Further, when DR2 and monoclonal antibody were incubated as the primary antibody, no band was obtained on immunoblotting (Fig. 4, lane 7). These results indicate that the isolated monoclonal antibody recognizes aa 30-109 of BRab8.

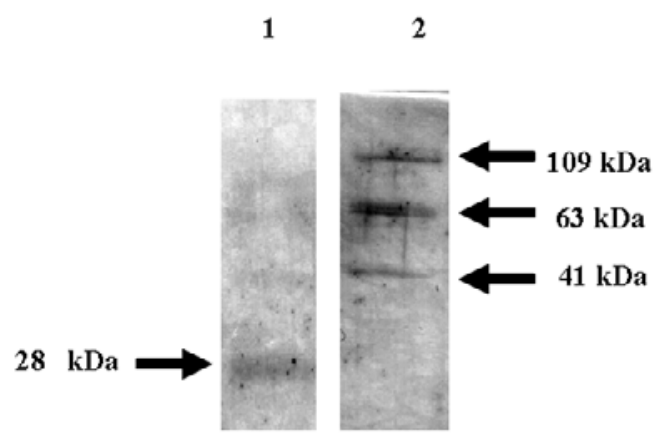

Fig. 6. Far-Western blotting. After electrophoresis, proteins $(10 \mu \mathrm{g})$ were transferred to a nitrocellulose membrane and incubated with BRab8 (lane 2). After washing, they were incubated with antibody against BRab8. Lane 1, no interacting protein was added. The arrows indicate BRab 8 protein (lane 1) and interacting proteins (lane 2).

\section{Immunoblotting using monoclonal antibody}

Next we examined whether the antibody recognized BRab8 in the tissue of B. mori. The brain homogenate was electrophoresed and immunoblotted with the antibody. It showed one band on immunoblots (Fig. 5, lane 2 ), and none in the control (lanes 3,4). The specific region (aa 30-109) recognized by clone 1 is conserved among Rab8 proteins (Itzen et al., 2006). The antibody also recognized Rab8 from the brain of rat (lane 5).

\section{Far-Western blotting using monoclonal antibody}

To identify proteins that interact with BRab8, farWestern blotting analysis, was used, which detects interacting proteins on a nitrocellulose membrane. Brain extract was electrophoresed, transferred, incubated with purified BRab8 protein and immunoblotted using monoclonal antibody. No protein except BRab8 (28 kDa) was detected in the control (Fig. 6, lane 1). Three proteins interacting with BRab8 $(41,62$, and $109 \mathrm{kDa}$, but not 28 $\mathrm{kDa}$ ) were detected (lane 2). After incubation of the membrane with BRab 8 protein and washing, BRab8 on the membrane may have remained non-specifically and reacted with the antibody to BRab8. So the band of 28 $\mathrm{kDa}$ might not be detected. These results suggest that proteins that interact with BRab8 occur in the brain of $B$. mori.

\section{DISCUSSION}

Rab8 regulates membrane transport and is involved in various cellular processes. Rab8 in human platelets is phosphorylated by thrombin in vivo (Karniguian et al., 1993), BRab8 is phosphorylated by PKC in vitro (Uno et al., 2006), and activation by PKC results in polarized distribution of Rab8 (Hattula et al., 2002), but there is no report of phosphorylation of insect Rab8 in vivo.

To identify the physiological characteristics of BRab8, a highly sensitive monoclonal antibody was isolated (Fig. 1). The antibody was insensitive to other Rab proteins and specific to Rab8 (Fig. 2). The region containing aa 30-109 was specifically recognized (Figs 3, 4). That region contains switch regions I and II, which change the conformation of Rab upon GTP or GDP binding. These regions contain a site that binds with effector proteins such as MSS4, which is a guanine nucleotide exchange factor. The antibody might inhibit interaction between Rab and effector proteins, and its injection into insects may inhibit membrane transport of neuropeptides or cause embryonic or morphogenetic defect.

Immunoblotting of brain extract specifically detected one band in B. mori (Fig. 5, lane 1) and one band in rat (lane 5). This result suggests that the antibody could be used to detect mammalian Rab8 protein. Using a Pro-Q Diamond phosphoprotein stain, we detected phosphorylated BRab8 protein in vivo (data not shown). Immunoprecipitation experiments with the antibody will also show phosphorylation of Rab8 protein in vivo.

$\mathrm{Rab}$ interacts with various proteins and regulates diverse cellular functions (Burton et al., 1994; Rak et al., 2003; Eathiraj et al., 2005; Grosshans et al., 2006). Three 
proteins that interact with BRab8 in the tissue of $B$. mori were detected using far-Western blotting (Fig. 6). Further studies are in progress to identify these proteins by mass spectrometry. Conditions for far-Western blotting may denature protein in the brain, and purified BRab8 may not be the active GTP-bound form. So GST pull-down analysis and immunoprecipitation will be needed to identify those proteins that interact with BRab8. We will use the antibody to examine the distribution of BRab8 in the tissues of B. mori.

ACKNOWLEDGEMENT. This work was supported in part by a Grant-in-Aid for Research in Priority Areas, 18580055, from the Ministry of Education, Science, Sports and Culture of Japan.

\section{REFERENCES}

Burton J.L., Burns M.E., Gatti E., Augustine G.J. \& De Camilli P. 1994: Specific interaction of Mss4 with members of the Rab GTPase subfamily. EMBO J. 13: 5547-5558.

Chabrillat M.L., Willhelm C., Wasmeiere C., Sviderskaya E.V., Louvard D. \& Coudrier E. 2005: Rab8 regulates the actin-based movement of melanosomes. Mol. Biol. Cell 16: $1640-1650$.

Debasmita P.A., Anand K.T., Lolitika M., Mingfa L., Bernard M.M. \& JAGAT K.R. 2005: Rab11 is required during Drosophila eye development. Int. J. Dev. Biol. 49: 873-879.

DeneKa M., Neeft M. \& VAN DeR Sluijs P. 2003: Regulation of membrane transport by rab GTPases. Crit. Rev. Biochem. Mol. Biol. 38: 121-142.

Ding J., Soule G., Overmeyer J.H. \& Maltese W.A. 2003: Tyrosine phosphorylation of the Rab24 GTPase in cultured mammalian cells. Biochem. Biophys. Res. Commun. 312: 670-675.

Dollar G., Struckhoff E., Michaud J. \& Cohen R.S. 2002: Rab11 polarization of the Drosophila oocyte: a novel link between membrane trafficking, microtubule organization, and oskar mRNA localization and translation. Development 129: 517-526.

Eathiraj S., Pan X., Ritacco C. \& Lambright D.G. 2005: Structural basis of family-wide Rab GTPases recognition by rabenosin-5. Nature 436: 415-420.

Gerges N.Z., Backos D.S. \& Esteban J.A. 2004: Local control of AMPA receptor trafficking at the postsynaptic terminal by a small GTPase of the Rab family. J. Biol. Chem. 279: 43870-43878.

Grosshans B.L., Ortiz D. \& Novick P. 2006: Rabs and their effectors: achieving specificity in membrane traffic. Proc. Natl. Acad. Sci. USA 32: 11821-11827.

Hattula K. \& Peranen J. 2000: FIP-2, a coiled-coil protein, links Huntington to Rab8 and modulates cellular morphogenesis. Curr. Biol. 10: 1603-1606.

Hattula K., Furuhjelm J., Arffman A. \& Peranen J. 2002: A Rab8-specific GDP/GTP exchange factor is involved in actin remodeling and polarized membrane transport. Mol. Biol. Cell 13: $3268-3280$.

Huber L.A., Pimplikar S., Parton R.G., Virta H., Zerial M. \& SimONS K. 1993: Rab8, small GTPase involved in vesicular traffic between the TGN and the basolateral plasma membrane. J. Cell. Biol. 123: 35-45.

Huber L.A., Dupree P. \& Dotti C.G. 1995: A deficiency of the small GTPase rab8 inhibits membrane traffic in developing neurons. Mol. Cell Biochem. 15: 918-924.
Itzen A., Pylypenko O., Goody R.S., Alexandrov K. \& Rak A. 2006: Nucleotide exchange via local protein unfolding structure of Rab8 in complex with MSS4. EMBO J. 25: $1445-1455$.

Jordens I., Marsman M., KuiJl C. \& Neefjes J. 2005: Rab proteins connecting transport and vesicle fusion. Traffic 6: 1070-1077.

Kametani F., Usami M., Tanaka K., Kume H. \& Mori H. 2004: Mutant presenilin (A260V) affects Rab8 in PC12D cell. Neurochem. Int. 44: 313-320.

Karniguian A., Zahraoui A. \& Tavitian A. 1993: Identification of small GTP-binding rab proteins in human platelets: thrombin-induced phosphorylation of rab3B, rab6 and rab8 proteins. Proc. Natl. Acad. Sci. USA 90: 7647-7651.

LAEMMLI U.K. 1970: Cleavage of structural proteins during the assembly of the head of bacteriophage T4. Nature 227: $680-685$.

Lowry O.H., Rosenbrough N.J., Farr A.L. \& Randall RJ. 1951: Protein measurement with the Folin phenol reagent. $J$. Biol. Chem. 193: 265-275.

Pelissier A., Chauvin J.P. \& Lecuit T. 2003: Trafficking through Rab11 endosomes is required for cellularization during Drosophila embryogenesis. Curr. Biol. 13: 1858-1857.

Pereira-Leal J.P. \& Seabra M.C. 2000: The mammalian rab family of small GTPases: definition of family and subfamily sequence motifs suggests a mechanism for functional specificity in the ras superfamily. J. Mol. Biol. 301: 1077-1087.

Rak A., Pylypenko O., Durek T., Watzke A., Kushnir S., Brunsveld L., Waldmann H., Goody R.S. \& Alexandrov K. 2003: Structure of Rab GDP-dissociation inhibitor in complex with prenylated YPT1GTPase. Science 302: 646-650.

Sahlender D.A., Roberts R.C., Arden S.D., Spudich G., Taylor M.J., Luzio J.P., Kendrick-Jones J. \& Buss F. 2005: Optineurin links myosin VI to the Golgi complex and is involved in Golgi organization and exocytosis. J. Cell. Biol. 169: $285-295$.

Satoh A.K., Tokunaga F., Kawamura S. \& Ozaki K. 1997: In situ inhibition of vesicle transport protein processing in the dominant negative Rab1 mutant of Drosophila. J. Cell Sci. 110: 2943-2953.

Satoh A.K., Otousa J.E., Ozaki K. \& Ready D.F. 2005: Rab11 mediates post-Golgi trafficking of rhodopsin to the photosensitive apical membrane of Drosophila photoreceptor. Development 132: 1487-1497.

Shetty K.M., Kurada P. \& Otousa J.E. 1998: Rab6 regulation rhodopsin transport in Drosophila. J. Biol. Chem. 273: 20425-20430.

Uno T., Nakao A. \& Katsurauma C. 2004: Phosphorylation of Rab proteins from the brain of Bombyx mori. Arch. Insect Biochem. Physiol. 57: 68-77.

Uno T., Nakao A., Fujiwara Y., Katsurauma C., Nakada T. \& Iтон O. 2006: Molecular cloning and expression of protein kinase C from Bombyx mori. Arch. Insect Biochem. Physiol. 61: 755-761.

Wucherpfennig T., Wilsch-Brauninger M. \& Gonzalez-Gaitan M. 2003: Role of Drosophila Rab5 during endosomal trafficking at the synapse and evoked neurotransmitter release. $J$. Cell Biol. 161: 609-624.

Zerilal M. \& McBride H. 2001: Rab proteins as membrane organizer. Nat. Rev. Mol. Cell Biol. 2: 107-117.

Received March 22, 2007; revised and accepted June 7, 2007 